\title{
Water-based lubrication of niobium nitride
}

\author{
Kaifei MIAO ${ }^{1}$, Jia WANG ${ }^{2, *}$, Qiang ZHAO ${ }^{1}$, Kaiwen WANG ${ }^{1}$, Mao WEN ${ }^{1}$, Kan ZHANG ${ }^{1, *}$ \\ ${ }^{1}$ State Key Laboratory of Superhard Materials, Department of Materials Science, Key Laboratory of Automobile Materials, MOE, Jilin \\ University, Changchun 130012, China \\ ${ }^{2}$ Department of Materials Science and Engineering, Jilin Jianzhu University, Changchun 130118, China \\ Received: 05 September2020 / Revised: 02 December 2020 / Accepted: 15 January 2021 \\ (C) The author(s) 2021.
}

\begin{abstract}
Water-based lubrication has attracted wide attention as an oil-free lubrication method owing to its greener and cleaner lubrication means. However, due to operating in the water environment, most moving parts would inevitably suffer from abrasion, rusting, and aging problems. Developing a novel solid-water composite system with ultra-low friction and wear will open new possibilities for innovative lubrication material research and development. Here, we first revealed the water-based lubrication behavior of a high-hardness niobium nitride coating $(\mathrm{NbN})$. In a three-phase contact environment (water, air, and $\mathrm{NbN}$ ), oxidation and hydrolytic reactions of $\mathrm{NbN}$ result in the formation of "colloidal solutions", containing $\mathrm{Nb}_{2} \mathrm{O}_{5}$ colloidal particles between the tribo-pairs. Utilizing the double electric layer repulsion and weak shear action of the "colloidal solution", $\mathrm{NbN}$ achieves ultra-low friction and wear; the corresponding values are as low as 0.058 and $1.79 \times 10^{-10} \mathrm{~mm}^{3} \cdot \mathrm{N}^{-1} \cdot \mathrm{m}^{-1}$, respectively. In addition, other VB transition metal nitrides (VB TMNs) exhibit the same low friction feature as $\mathrm{NbN}$ in the three-phase contact environment; the friction coefficients are even lower than those in an oil-based environment. The water-based lubrication of VB TMNs provides a new reliable scheme for optimizing solid-water composite lubrication systems without additives and is expected to be applied in environments with high humidity or insufficient water coverage.
\end{abstract}

Keywords: $\mathrm{NbN}$; water-based lubrication; ultra-low friction; ultra-low wear

\section{Introduction}

Water-based lubrication can effectively save natural resources and ensure the normal operation of mechanical equipment in a clean environment. Compared with traditional oil lubrication, water-based lubrication is a greener and cleaner lubrication method. However, there remains a disparity between the lubricating ability of water and oil [1-3]. Adding additives to water is an effective method of improving its water-based lubrication ability [4, 5]. Various two-dimensional layered materials, such as the combination of black phosphorus and graphene oxide [6] or graphene oxide and ethanediol [7], have been added to water to reduce friction by the typical weak shear properties of layered materials. In addition, polyhydroxy acids $[8,9]$, ionic liquids $[4,10,11]$, or the combination of acids and organic alcohols [12] also exhibit outstanding lubrication properties in water environments by forming a hydration layer and electrostatic repulsion. However, in actual engineering conditions, waterbased lubrication with additives will face many problems. For layered additives, dispersibility in water is a key factor in restricting their lubricating ability $[13,14]$, and additives need to be added in time to prevent lubrication failure. Furthermore, materials commonly used in moving parts, such as metals and engineering plastics [15, 16], are often at risk of failure due to severe wear caused by corrosion or microstructure aging when exposed to water for a

* Corresponding authors: Kan ZHANG, E-mail: kanzhang@jlu.edu.cn; Jia WANG, E-mail: wangjia@jlu.edu.cn 
long time. In particular, acid-based lubrication further increases the risk of failure [7, 8]. As a moving part itself, chemical reactions within the environment or media should be avoided as far as possible to reduce the probability of component damage, shortened life, or safety accidents caused by consumption. From a protective mechanical equipment perspective, the deposition of protective coatings with excellent mechanical properties and water-based lubricating behavior on the surface of a moving part should be a simpler and more effective method than the scheme for optimizing the water environment.

According to recent research on TMNs in our group, TMNs possess prominent high hardness, wear resistance, and chemical inertness features [17-19], which make them widely used in cutting protective coatings [20, 21], scratch-resistant devices [22], hard components of metal-matrix composites, and anticorrosive coatings [23, 24]. The excellent mechanical properties and environmental stability of TMNs indicate that they have great application potential as protective coatings in water environments. However, few studies have focused on TMNs as the lubricant material; in particular, the tribological behaviors of TMNs in water environments, are unclear. Here, we prepared three typical VB TMNs ( $\mathrm{NbN}, \mathrm{VN}$, and TaN) and found some interesting phenomena when studying the tribological behavior in water. The VB TMNs exhibit outstanding water-based lubricating behavior when simultaneously exposed to water and air and their friction properties are superior to those of similar nitride coatings in a solid-oil composite lubrication system [25]. The $\mathrm{NbN}$ coating was selected as a representative to conduct the corresponding mechanism research, which suggests that the tribochemical reactions among the coating, air, and water contribute to the ultra-low friction. Moreover, VB TMNs with high hardness attained an ultra-low wear rate of $\sim 10^{-10} \mathrm{~mm}^{3} \cdot \mathrm{N}^{-1} \cdot \mathrm{m}^{-1}$. These findings identify the VB TMNs as a mechanically strong coating material that exhibits outstanding water-based lubrication behavior, with simultaneous non-additive lubricating functionality and superior protection, guaranteeing the service life and safety of mechanical equipment in an environment with highhumidity or inadequate water cover; the material shows great potential for applications ranging from microdevices to large-scale industrial equipment.

\section{Experimental}

\subsection{Coating preparation}

The VB TMNs were deposited on polished Si(100) substrates using a DC reactive magnetron sputtering system. Individual targets of transition metals $(\mathrm{Nb}$, $\mathrm{Ta}$, and $\mathrm{V}$ ) with a diameter of $60 \mathrm{~mm}$ were used as source materials. The substrates were ultrasonically cleaned in acetone, alcohol, and distilled water in an ultrasonic bath for $20 \mathrm{~min}$ and then inserted into the substrate holder. Prior to deposition, the system was evacuated to a base pressure of $1 \times 10^{-4}$ Pa using a turbomolecular pump. To remove the surface adventitious contamination, the targets were presputtered with $\mathrm{Ar}^{+}$for $10 \mathrm{~min}$. During all depositions, the mixing gas ( $\mathrm{Ar}$ and $\mathrm{N}_{2}$ ) pressure was maintained at $0.8 \mathrm{~Pa}$ by controlling the pumping speed with a throttling value. The targets were powered by direct current and the sputtering current on the targets was maintained at $0.4 \mathrm{~A}$. The deposition parameters are listed in Table 1. By adjusting the deposition time, the thickness of all coatings was controlled at approximately $1.7 \mu \mathrm{m}$.

\subsection{Characterization}

The phase structures of the VB TMNs were characterized by X-ray diffraction (XRD) using a Bragg-Brentano diffractometer (D8 tools) in the $\theta-2 \theta$ configuration, with $\mathrm{Cu} \mathrm{K} \alpha$ radiation. The microstructure was further identified by the high-resolution transmission electron microscope (HRTEM, field emission JEOL 2100F, Japan). The surface morphology coupled with root-mean-square roughness $\left(R_{\mathrm{q}}\right)$ was obtained by an atomic force microscope (AFM, Dimension Icon, USA). The intrinsic hardness $(H)$ and elastic modulus $(E)$ of the coatings were evaluated by an MTS Nanoindenter XP nanoindentation system, with a continuous stiffness measurement (CSM) mode. A

Table 1 Summary of the deposition parameters of VB TMNs.

\begin{tabular}{ccccc}
\hline Sample & Target & $\begin{array}{c}\text { Target power } \\
(\mathrm{W})\end{array}$ & $\begin{array}{c}\mathrm{Ar}_{2}: \mathrm{N}_{2} \\
(\mathrm{sccm})\end{array}$ & $\begin{array}{c}\text { Temperature/ } \\
\text { Bias }\end{array}$ \\
\hline $\mathrm{NbN}$ & $\mathrm{Nb}$ & 90 & $70: 10$ & $200^{\circ} \mathrm{C} /-80 \mathrm{~V}$ \\
$\mathrm{TaN}$ & $\mathrm{Ta}$ & 90 & $70: 20$ & $200^{\circ} \mathrm{C} /-80 \mathrm{~V}$ \\
$\mathrm{VN}$ & $\mathrm{V}$ & 90 & $60: 30$ & $200^{\circ} \mathrm{C} /-80 \mathrm{~V}$ \\
\hline
\end{tabular}


3-side pyramid Berkovich tip indented the coatings to a maximum of $600 \mathrm{~nm}$ and $H$ and $E$ were taken at a depth of approximately $40-90 \mathrm{~nm}$. To minimize data error, at least six indentations were set on each sample.

\subsection{Tribological tests}

The tribological behaviors of the VB TMNs were determined by sliding a $6.0 \mathrm{~mm}$ diameter stainless steel ball on a CSM ball-on-disc tribometer at room temperature $\left(27^{\circ} \mathrm{C}\right)$, with a relative humidity of $32 \%$, where the diameter of the sliding track, normal load, and sliding speed was fixed at $4 \mathrm{~mm}, 1 \mathrm{~N}$, and $1 \mathrm{~cm} / \mathrm{s}$, respectively. After friction tests, the wear depth of the sample was examined using a surface profiler (Veeco Dektak 150, USA). The wear track morphology was observed using an optical microscope (Leica DFC450 C, Germany). The roughness of the wear track and wear scar were measured using a three-dimensional profiler (Olympus OL3000, Japan). The oxidation states of $\mathrm{NbN}$ before and after the friction test were analyzed by an X-ray photoelectron spectroscope (XPS, ESCALAB-250, USA), using Al $\mathrm{K} \alpha$ as the X-ray source, with an energy of $1 \mathrm{keV}$. Raman characterization using a Renishaw-1000 spectrometer with a $514 \mathrm{~nm}$ line from an $\mathrm{Ar}-\mathrm{Kr}$ ion laser was also conducted to investigate the chemical compositions of the friction products at the wear track. The laser output power was set to $1,000 \mathrm{~mW}$. The $\mathrm{pH}$ value of the "colloidal solution" between the friction interfaces was measured by a $\mathrm{pH}$ meter (AZ 8692). The viscosity of the "colloidal solution" was measured via an advanced rotary rheometer (Anton Paar MCR 92, Austria) at $25{ }^{\circ} \mathrm{C}$, without changing the $\mathrm{pH}$ value.

\section{Results and discussion}

\subsection{Composition and phase structure}

Utilizing magnetron sputtering equipment, $\mathrm{NbN}$ with good crystallization can be obtained if the deposition temperature is properly increased. As shown in Fig. $1(\mathrm{a})$, the peaks at $35.7^{\circ}, 41.3^{\circ}$, and $60.1^{\circ}$, which are dominated by c-NbN (111), c-NbN (200), and c-NbN (220) orientations, respectively (PDF\# 65-9399), appear in the XRD pattern over the $2 \theta$ range of $30^{\circ}-65^{\circ}$, indicating the formation of a cubic $\mathrm{NaCl}$-structure $\mathrm{NbN}$. According to the HRTEM results shown in Fig. 1(b), c-NbN (111), and c-NbN (200), with interplanar spacings $(d)$ of 0.248 and $0.214 \mathrm{~nm}$, respectively, are observed; this further verifies the XRD results. The surface three-dimensional image of $\mathrm{NbN}$ is shown by AFM in Fig. 1(c). It was found that the $\mathrm{NbN}$ surface exhibits clear island-like undulations and there are many grooves around the protrusions $\left(R_{\mathrm{q}} \approx 5.54 \mathrm{~nm}\right)$. The appearance of hillocks is usually related to the typical columnar growth of $\mathrm{NbN}$ [26]. In addition, mechanical characterization (Fig. S1 in the Electronic Supplementary Material (ESM)) demonstrates that the $\mathrm{NbN}$ with good crystallization also possesses excellent mechanical properties; the corresponding hardness and elasticity modulus are $23.74 \pm 0.58 \mathrm{GPa}$ and $288.33 \pm 4.48 \mathrm{GPa}$, respectively.

\subsection{Tribological behavior}

To study the effect of water on the tribological behavior
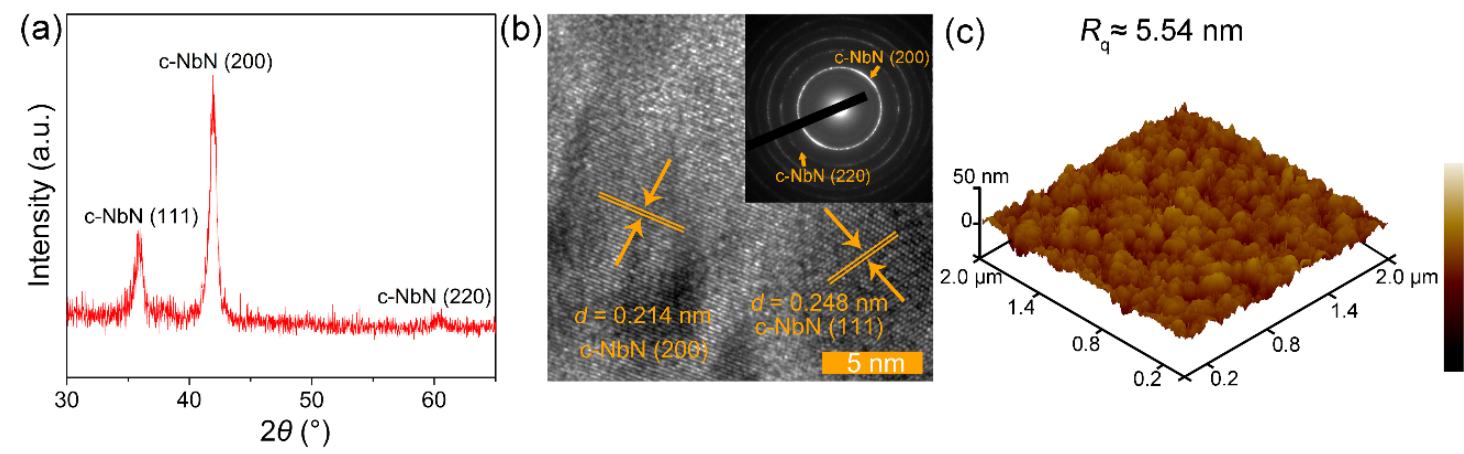

Fig. 1 (a) XRD pattern in the $\theta-2 \theta$ mode for the $\mathrm{NbN}$; (b) typical HRTEM image for $\mathrm{NbN}$, the interplanar spacings $(d)$ are marked on the image; the inset shows its selected area (electron) diffraction (SAED) pattern; and (c) AFM 3D micrograph in the dimension of $2 \mu \mathrm{m} \times 2 \mu \mathrm{m}$ for $\mathrm{NbN}$, the root-mean-square roughness $\left(R_{\mathrm{q}}\right)$ is also marked. 
of $\mathrm{NbN}$, three friction environments, including threephase contact, dry friction in the atmosphere, and full water-covered were constructed by controlling the amount of water between the friction interfaces. Here, a pipette was used to drop approximately $5 \mu \mathrm{L}$ of deionized water onto the contact area between the tribo-pairs to achieve three-phase contact; a clear diagram is presented in Fig. 2(a). Compared to the dry friction in the atmosphere and a full water-covered environment, a three-phase contact environment allows the friction interfaces to maintain contact with both air and water during the sliding process owing to the participation of a small amount of water. Thus, a three-phase contact of solid $(\mathrm{NbN})$, liquid (water), and gas (air) is formed. In the as-modified environment, $\mathrm{NbN}$ presents a very stable ultralow-friction feature, as shown in Fig. 2(b), with an average value as low as 0.058 . In contrast, in a dry friction environment, the friction feature of $\mathrm{NbN}$ is much higher. After the run-in period, the friction coefficient rises linearly and remains at approximately 0.78 for a long time. Regarding the full water-covered environment, the friction coefficient of $\mathrm{NbN}$ exhibits a significant downward trend and its average value can be reduced to approximately
0.61 over the entire friction cycle. That is, the friction coefficient in the three-phase contact reduces by one order of magnitude. To verify the repeatability of the ultralow-friction phenomenon and the relationship between the test environment and friction performance of $\mathrm{NbN}$, multiple repeated tests were performed and the corresponding results are counted in the form of a point distribution in Fig. 2(c). In the three-phase contact environment, the average value is maintained between 0.04 and 0.09 . In the other two comparison environments, the mean friction coefficient of $\mathrm{NbN}$ fluctuated within the range of $0.47-0.87$, with great dispersion. The reduction of one order of magnitude in the friction coefficient further proves that the excellent ultra-low friction performance of $\mathrm{NbN}$ in a three-phase contact environment is not accidental.

The three-phase contact allows $\mathrm{NbN}$ to give full play to its outstanding ultra-low friction ability; its excellent anti-wear ability is also highlighted. According to the optical microscope images shown in Fig. 3(a), after 10,000 laps of testing, $\mathrm{NbN}$ inevitably shows slight wear and there is no significant accumulation of wear debris around the wear track. Through further measurement, it was determined that the width of
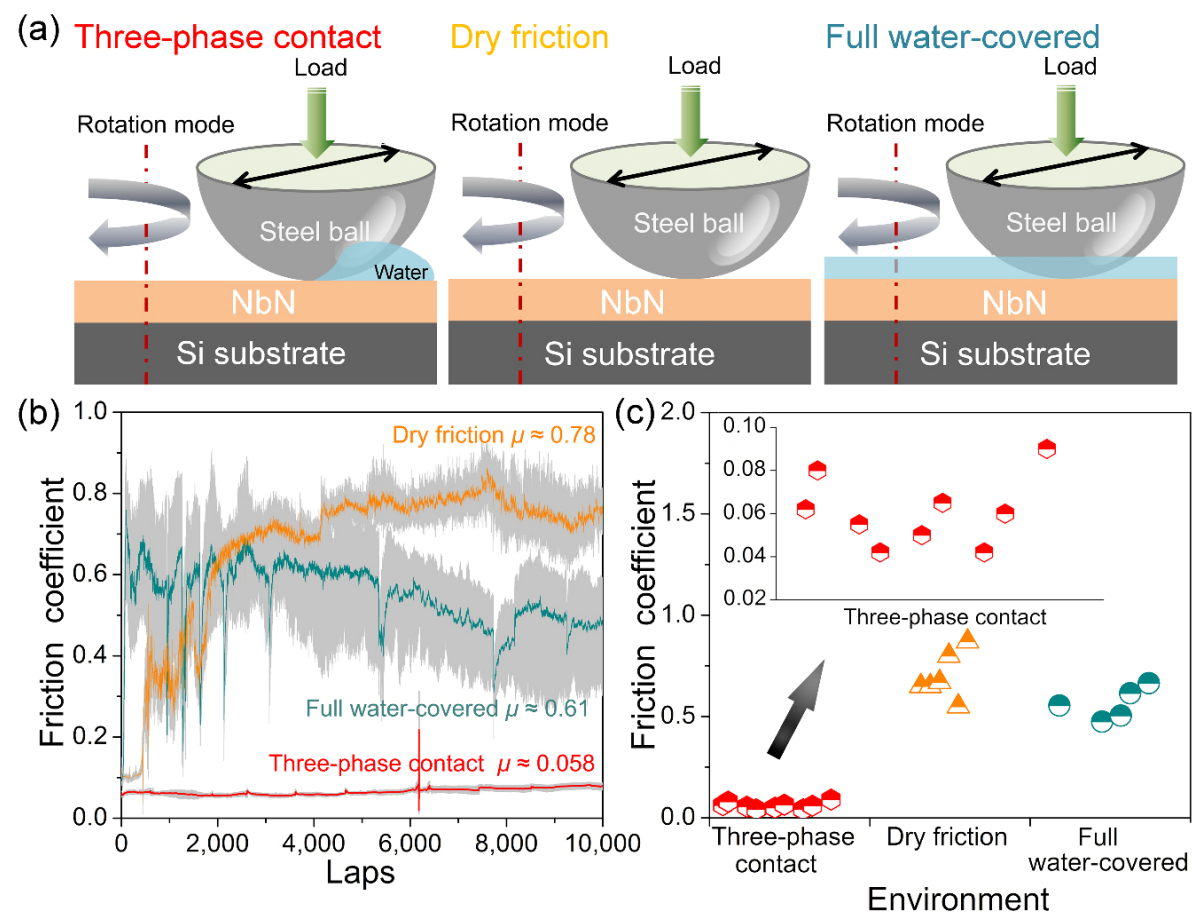

Fig. 2 (a) Schematic diagram of the friction test equipment, with the ball-on-disk rotating mode in three friction environments; (b) measured friction coefficient $\mu$ vs. the number of cycles while sliding a stainless steel ball on $\mathrm{NbN}$; and (c) friction coefficient distribution of $\mathrm{NbN}$ after multiple repeated tests. 

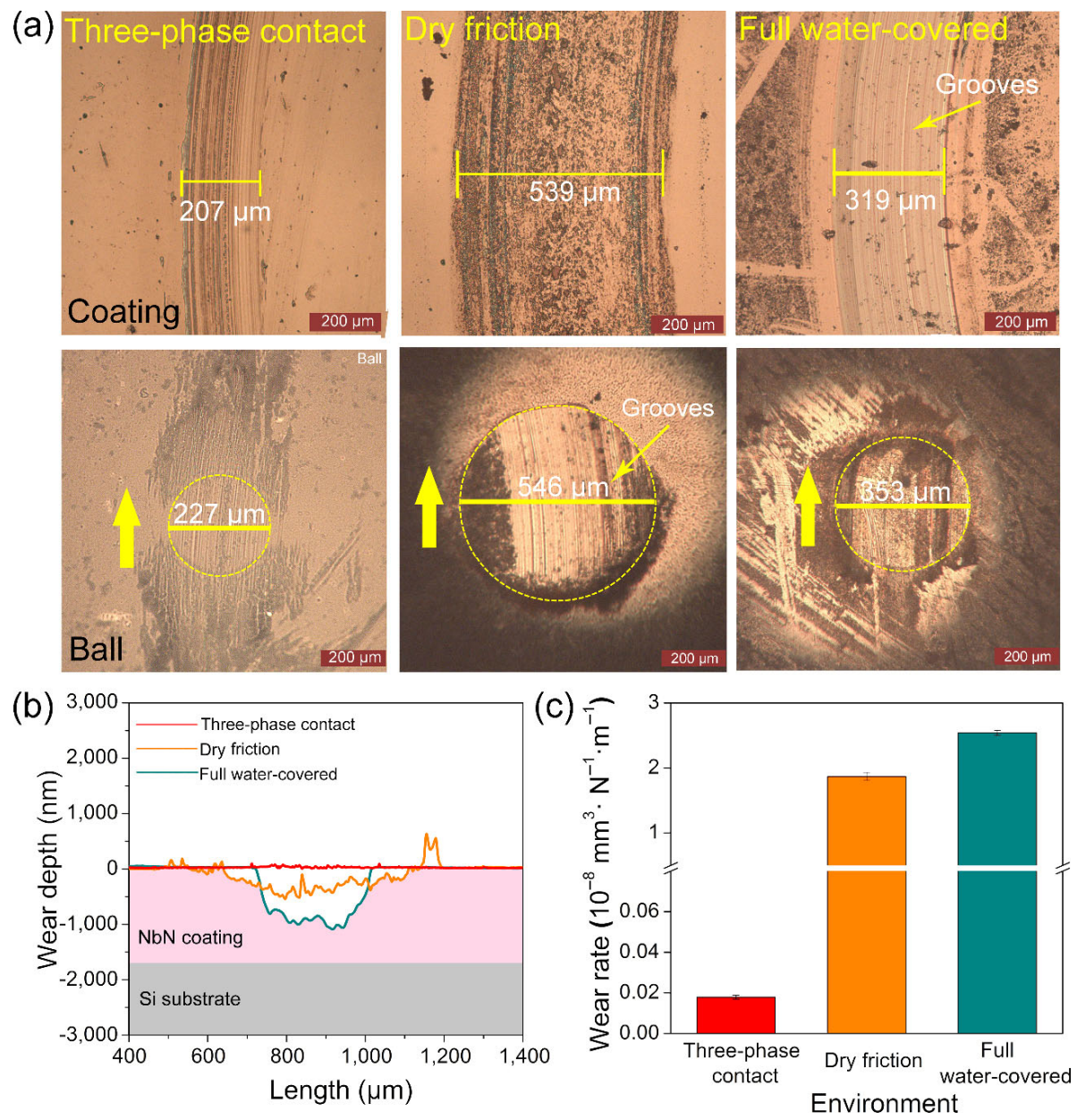

Fig. 3 (a) Optical microscope images of the $\mathrm{NbN}$ wear tracks and the counterpart ball wear scars after tribo-tests in three environments; (b) cross-sectional views of $\mathrm{NbN}$ wear tracks; and (c) wear rates of $\mathrm{NbN}$ after tribo-tests in three environments.

the wear track was approximately $207 \mu \mathrm{m}$ and the diameter of the wear scar of the counterpart ball is approximately $227 \mu \mathrm{m}$, which is consistent with the width of the wear track. In addition, along the shear direction of the counterpart ball, it can be found that a small amount of dark wear debris accumulation appears at the front and back of the wear scar. Using a surface profiler, the deepest depth of the wear track was measured as approximately $65 \mathrm{~nm}$, as shown in Fig. 3(b), which also confirms the shallow wear track. By further fitting and calculation, the resulting wear rate of $\mathrm{NbN}$ in a three-phase contact environment is as low as $1.79 \times 10^{-10} \mathrm{~mm}^{3} \cdot \mathrm{N}^{-1} \cdot \mathrm{m}^{-1}$. However, in the other two test environments, $\mathrm{NbN}$ exhibits more serious wear phenomena with different degrees. The surface of the wear track in dry friction exhibits obvious wear and a large amount of wear debris is randomly attached in the wear track area. The wear track width is up to approximately $539 \mu \mathrm{m}$ and the diameter of the wear scar of the counterpart ball is approximately $546 \mu \mathrm{m}$. Furthermore, distinct grooves can be observed on the wear scar surface. The deepest depth of the wear track is also up to $563 \mathrm{~nm}$ and the corresponding wear rate is approximately $1.49 \times 10^{-8} \mathrm{~mm}^{3} \cdot \mathrm{N}^{-1} \cdot \mathrm{m}^{-1}$. Regarding the full water-covered environment, the wear of $\mathrm{NbN}$ becomes more severe and there is no debris accumulation around the wear track. The wear track width is approximately $319 \mu \mathrm{m}$ and the counterpart ball also has distinct grooves and is approximately $353 \mu \mathrm{m}$ in diameter. According to the cross-sectional view of the wear track, the deepest depth of the wear track reaches $1,107 \mathrm{~nm}$ and the corresponding wear rate is approximately $2.63 \times 10^{-8}$ $\mathrm{mm}^{3} \cdot \mathrm{N}^{-1} \cdot \mathrm{m}^{-1}$. As presented in Fig. 3(c), compared with the other two environments, the wear rate for three-phase contact has been reduced by at least two 
orders of magnitude, indicating that $\mathrm{NbN}$ has ultra-low friction and ultra-low wear in the as-modified environment.

\subsection{Friction mechanism}

Experimental results show that constructing different friction environments could regulate the tribological behavior of $\mathrm{NbN}$ and the tribological properties of $\mathrm{NbN}$ are greatly improved by simply dropping the water method. Regarding the test environment, the biggest characteristic of three-phase contact is that the tribo-pairs can simultaneously contact the air and water during the friction process. To some extent, this environmental difference determines the direction of the tribochemical reaction at the friction interfaces, which may be the key factor affecting the tribological behavior of $\mathrm{NbN}$. To further analyze the friction mechanism, XPS and Raman characterizations of the $\mathrm{NbN}$ and counterpart ball after the friction tests were conducted. Figure 4(a) shows the schematic diagram of the test points on the friction interfaces for XPS and Raman. "a," "b" and "c" in Fig. 4(a) represent the original $\mathrm{NbN}$ coatings, the center, and edge positions of the wear track, respectively; " $\mathrm{d}$ " and " $\mathrm{e}$ " in Fig. 4(a) represent the center and edge positions of the wear scar of the counterpart ball, respectively. The XPS spectra of $\mathrm{N} 1 \mathrm{~s}$ and $\mathrm{Nb} 3 \mathrm{~d}$ are displayed in Figs. 4(b) and $4(\mathrm{c})$. On the original $\mathrm{NbN}$ area, the $\mathrm{Nb}-\mathrm{N}$ bond (397.4, 206.2, and 203.6 eV) is detected [27-30]. On the center of the wear track, in addition to the $\mathrm{Nb}-\mathrm{N}$ peaks from the original coating, newly presented $\mathrm{Nb}-\mathrm{O}-\mathrm{N}$ peaks, which bond at 401.4, 399.3, 208.2, and $205.1 \mathrm{eV}$, have also been detected [27-29]. Furthermore, two peaks at 209.3 and $207.5 \mathrm{eV}$ in the $\mathrm{Nb} 3 \mathrm{~d}$ spectrum can be divided by the Gaussian function, which both belong to the $\mathrm{Nb}_{2} \mathrm{O}_{5}$ bond [27-29]. It is worth noting that although the intensity of the main peak of $\mathrm{Nb}-\mathrm{O}-\mathrm{N}$ is similar to that of the $\mathrm{Nb}-\mathrm{N}$ peak in the $\mathrm{N}$ $1 \mathrm{~s}$ spectrum, the intensity of the $\mathrm{Nb}_{2} \mathrm{O}_{5}$ peaks was, overall, much higher than that of the $\mathrm{Nb}-\mathrm{O}-\mathrm{N}$ peaks (a)
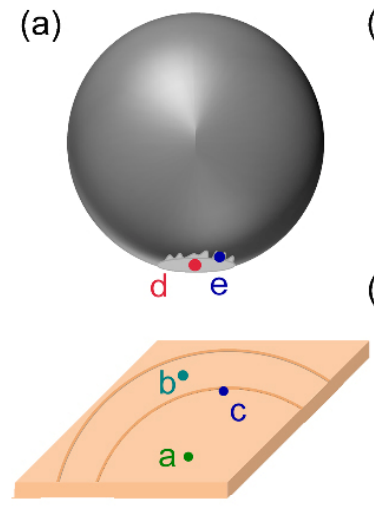

(c)
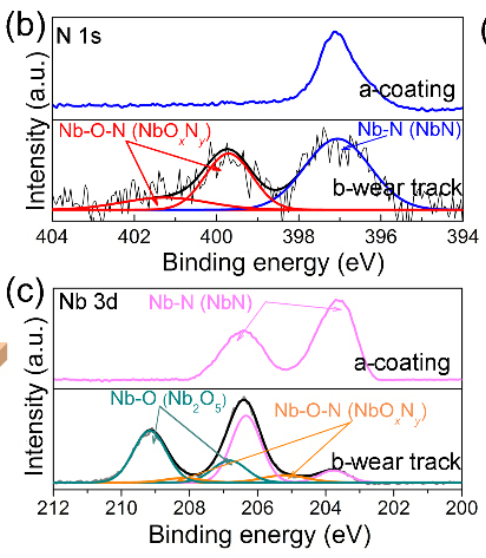

(d)

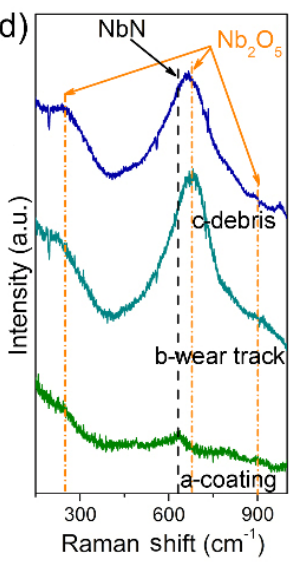

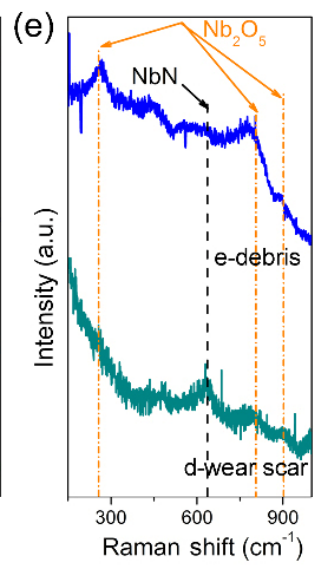
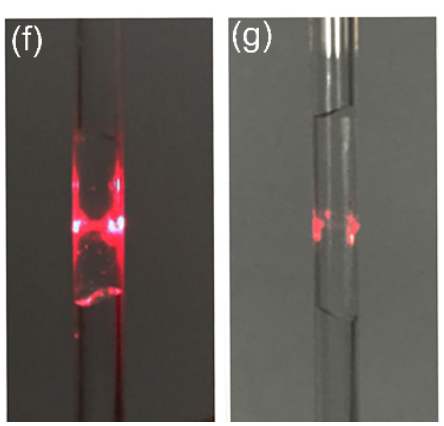

(h)
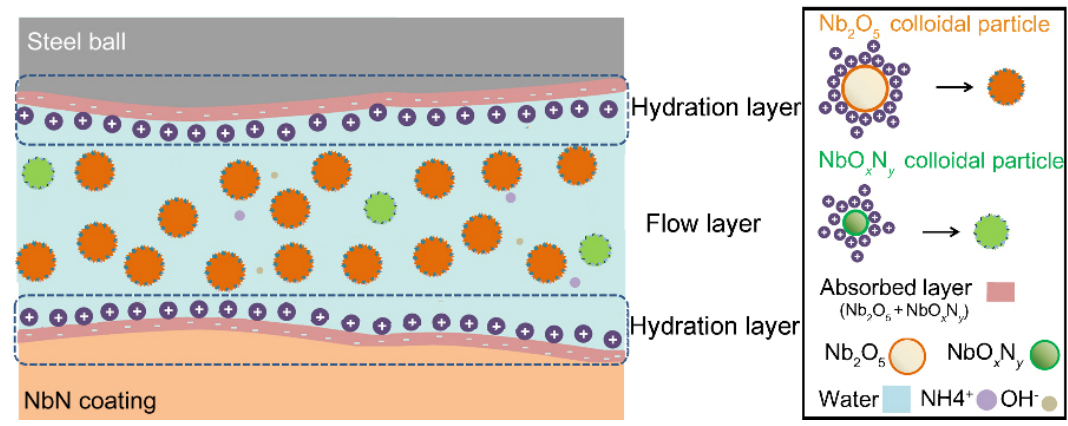

Fig. 4 (a) Simulation diagram of test points on the friction interfaces for XPS and Raman after tribo-tests in three-phase contact environment; (b) XPS N 1s spectra of original NbN and wear track; (c) XPS Nb 3d spectra of original NbN and wear track; (d) Raman spectra of original NbN, wear track, and wear debris; (e) Raman spectra of the counterpart ball wear scar and debris; (f) tyndall effect generated by the "colloidal solution" after friction test in three-phase contact; (g) disappearance of the Tyndall effect caused by the addition of an $\mathrm{NaCl}$ solution; and (h) schematic of the friction model of $\mathrm{NbN}$ in the three-phase contact environment. 
in the $\mathrm{Nb} 3 \mathrm{~d}$ spectrum. This suggests that friction promotes the oxidation reaction during the friction process and the main oxidation product is $\mathrm{Nb}_{2} \mathrm{O}_{5}$. The Raman results further confirm the above inference, as presented in Figs. 4(d) and 4(e). Three weak peaks are detected on the original $\mathrm{NbN}$ area; the peak located at $635 \mathrm{~cm}^{-1}$ can be assigned to $\mathrm{NbN}$ [31] and the other two peaks centered at 250 and $901 \mathrm{~cm}^{-1}$ belong to $\mathrm{Nb}_{2} \mathrm{O}_{5}[32,33]$. On the center and the edge positions of the wear track, a strong $\mathrm{Nb}_{2} \mathrm{O}_{5}$ peak appears at $680 \mathrm{~cm}^{-1}$ $[32,33]$. In addition, the $\mathrm{Nb}_{2} \mathrm{O}_{5}$ peaks on the edge of the wear scar, at 250,807 , and $901 \mathrm{~cm}^{-1}$, can be clearly detected [32-34], which is consistent with the wear debris accumulation observed in Fig. 3(a). In contrast, the intensity of the $\mathrm{Nb}_{2} \mathrm{O}_{5}$ peaks at the center of the wear scar is weaker and the $\mathrm{NbN}$ signal at $635 \mathrm{~cm}^{-1}$ is stronger. Therefore, the formation of $\mathrm{Nb}_{2} \mathrm{O}_{5}$ at the friction interface is an important component that affects the tribological behavior of $\mathrm{NbN}$ in a threephase contact environment. However, comparing the frictional performances in the other two environments, we can conclude that $\mathrm{Nb}_{2} \mathrm{O}_{5}$ is not the only factor.

It is known that environmental differences are another key component. In the atmosphere, the initial absorption and dissociation of oxygen on the VB TMN surface are exothermic, resulting in rapid coverage of the VB TMN surfaces by atomic oxygen. According to Ref. [35], there is a large number of available electrons near the Fermi level of the VB transition metal, locating the initial reaction activation site of oxygen on the VB TMN surface at the metal site. Therefore, oxidation starts from the defect sites on the VB TMN surface and the metal atoms and trace oxidation can occur spontaneously on the VB TMN surface. However, due to the existence of strong covalent bonds in TMN, when oxygen continues to diffuse into the TMN bulk, high energy is required for the N/O exchange to remove $\mathrm{N}$, creating an energy barrier for further oxidation [35, 36]. In our work, the three-phase contact environment provides the possibility for oxidation. During the friction process, shear action will cause a high flash temperature between tribo-pairs and then induce interfacial oxidation on the $\mathrm{NbN}$ surface. XPS and Raman results confirm that a large amount of $\mathrm{Nb}_{2} \mathrm{O}_{5}$ and a minute amount of $\mathrm{NbO}_{x} \mathrm{~N}_{y}$ are the typical friction products on the $\mathrm{NbN}$ wear track surface and the counterpart ball wear scar. In addition, in a charge-balanced system, tribochemical reactions must affect the $\mathrm{pH}$ value of the surrounding environment. To verify this hypothesis and elucidate the possible tribochemical reaction, the $\mathrm{pH}$ values of the water droplet between the friction interfaces before and after the test were measured using a $\mathrm{pH}$ meter. It was found that the $\mathrm{pH}$ value increases from $7.0 \pm 0.1$ to $7.8 \pm 0.1$ after the test. Based on the above results, the tribochemical process of $\mathrm{NbN}$ activated by shear action can be described as follows: $\mathrm{NbN}+\mathrm{H}_{2} \mathrm{O}+\mathrm{O}_{2} \rightarrow \mathrm{Nb}_{2} \mathrm{O}_{5}+\mathrm{NbO}_{x} \mathrm{~N}_{y}+\mathrm{NH}_{4}^{+}+$ $\mathrm{OH}^{-}$. In addition to being attached to the tribo-pair surfaces, the friction products are also incorporated into the water droplet to transform into the "colloidal solution" and the corresponding evidence is obtained by the Tyndall effect experiment [37]. As shown in Fig. 4(f), a series of luminous points are observed when a laser beam passes through the "colloidal solution", which can be attributed to the friction products scattering the light rays that fall on them. According to the Tyndall effect, it is preliminarily proven that a large number of friction products exist in colloidal form. When the electrolyte solution $(\mathrm{NaCl})$ is injected into the "colloidal solution", the discernible beam path disappears (Fig. 4(g)) because the colloidal stability of an electrostatically stabilized dispersion is broken down [37]. The above experiments are consistent with the classical "Derjaguin-Landau-Verwey-Overbeek" theory [38, 39], which proves that the friction products $\left(\mathrm{Nb}_{2} \mathrm{O}_{5}\right)$ present as colloidal particles in water. The "colloidal solution" becomes an excellent medium for obtaining low friction. The film thickness of "colloidal solution" between the tribopairs was estimated using the Hamrock-Dowson equation [40] in the ESM. The estimated film thickness under a sliding velocity of $1 \mathrm{~cm} / \mathrm{s}$ and $1 \mathrm{~N}$ normal load is approximately $36.3 \mathrm{~nm}$. The calculations in the ESM demonstrate that the ratio of the film thickness of "colloidal solution" to the combined surface roughness is in the range of $1-3$, and hence, the lubrication regime for tribo-contact is located in the mixed lubrication regime during the low friction period [41]. It can be concluded that in the three-phase contact environment, the friction products attached to the tribo-pair surfaces and the "colloidal solution" between the tribo-pairs together constitute 
the lubricating phase. The schematic model is shown in Fig. 4(h). On the tribo-pair surfaces, the attached friction products with negatively charged bridging oxygens can capture the positive electrical ions in the surrounding environment $[42,43]$ and so the upper and lower surfaces will remain positively charged, on the whole. Simultaneously, the attached friction products can also lock the water molecules by means of hydrogen bonds and so the upper and lower surfaces all have a fixed "hydration layer". Between the tribo-pair surfaces, a large number of friction products are dispersed in a "colloidal solution". The ability to capture the positive electrical ions in a "colloidal solution" enables the conversion of friction products into positively charged colloidal particles. The nature of positivity causes the colloidal particles to repel each other, which is the reason for the good dispersion of colloidal particles in "colloidal solutions". The various particles in a "colloidal solution" move with the movement of the bulk water molecules and remain dispersed to form a dynamic balance; thus, the whole "colloidal solution" can be regarded as a positively charged "flow layer". In essence, both the "fixed hydration layers" and "flow layer" belong to the "hydration layer" consisting of the "colloidal solution"; hence, the rheological properties of the "hydration layer" can be evaluated by characterizing the "colloidal solution". The friction linear velocity used in our work was $1 \mathrm{~cm} / \mathrm{s}$ so the corresponding shear rate was $0.796 \mathrm{~s}^{-1}$. In combination with the analysis of Fig. S2 in the ESM, the "hydration layer", consisting of the "colloidal solution", exhibits the characteristics of a Newtonian fluid. Compared with pure water (approximately $0.89 \mathrm{mPa} \cdot \mathrm{s}$ at $25^{\circ} \mathrm{C}$ ), the "colloidal solution" has a higher viscosity (approximately $32.05 \mathrm{mPa} \cdot \mathrm{s}$ ), which improves the poor film-forming and lubricating abilities of interfacial water due to its low viscosity [4]. In addition, the continuous fluidity of the colloidal solution is also better. During the friction process, the "flow layer" will naturally be repelled from the "hydration layers", which are fixed to the upper and lower surfaces. The repulsion interactions of electric double layers between the fixed "hydration layers" and "flow layer" - combined with the natural water-based weak shear capacity $[44,45]$ of the "flow layer" - is the fundamental reason for the ultra-low friction. Therefore, a solidwater composite lubrication system based on the water-based lubricating behavior of $\mathrm{NbN}$ was formed in a three-phase contact environment.

Moreover, the wear robustness of $\mathrm{NbN}$ is very prominent. First, it is closely related to the excellent mechanical properties of $\mathrm{NbN}$. Second, it is the oxidation feature of $\mathrm{NbN}$. As mentioned above, slight oxidation on the $\mathrm{NbN}$ surface can occur spontaneously but there is an energy barrier for oxygen to continue to diffuse into the $\mathrm{NbN}$ bulk and replace nitrogen. Friction can only promote the oxidation process of the $\mathrm{NbN}$ surface layer. Third, the special friction mode of $\mathrm{NbN}$ in the as-modified environment has a greater impact. The slight wear on the $\mathrm{NbN}$ surface comes from the initial stage of friction and the $\mathrm{NbN}$ consumed at the wear track is the only source of the lubrication phase between the friction interfaces. When sufficient friction products are distributed on the tribo-pair surfaces and in the "colloidal solution" to form stable ultra-low friction, the wear rate becomes very slow. Furthermore, the repulsion interactions of the electric double layers further alleviated the wear caused by the direct contact of the tribo-pairs. By measuring the area of the counterpart ball wear scar, the contact stress in the friction process is estimated to be approximately $24.5 \mathrm{MPa}$. The low contact stress also contributes to the reduction in friction and wear.

According to the above discussion, the water in the three-phase contact is the fundamental difference that determines the tribological behavior of $\mathrm{NbN}$. The method of dropping water provides two beneficial conditions for the formation of ultra-low friction. First, it can ensure timely contact of $\mathrm{NbN}$ with air (for the oxidation reaction) to continuously supply oxides; second, it is conducive to obtaining good dispersion and repulsion forces of the friction products in the "colloidal solution" with appropriate concentration. However, if the amount of water between the friction interfaces is too small or too large, it is difficult to obtain ultra-low friction for $\mathrm{NbN}$. In the case of dry friction with $32 \%$ humidity, an increasing number of friction products accumulate on the wear track surface and do not disperse well during the friction process, before inevitably sticking together to form wear debris; this increases the friction coefficient. At the same 
time, part of the debris accumulation in the wear track causes it to become uneven, which increases the friction fluctuation. However, in a fully watercovered environment, plenty of water brings three disadvantages to friction reduction. First, the $\mathrm{NbN}$ surface is isolated from the atmosphere by being covered with water, the oxidation reaction is limited, and the oxide supply is insufficient. Second, the low concentration of trace oxides in large amounts of water leads to the disappearance of repulsion and the shear force between the friction interfaces increases. Finally, the scouring effect of water flow makes it difficult for the newly formed oxide to adhere to the wear track stably, resulting in wear that cannot be alleviated. Thus, the three-phase contact environment is the ideal condition for $\mathrm{NbN}$ to achieve ultra-low friction. To prove that the particular tribological behavior originates from $\mathrm{NbN}$ itself and is independent of the dual material, we replaced the counterpart ball with $\mathrm{Al}_{2} \mathrm{O}_{3}$ and repeated the original experiment many times. The results in Fig. 5 demonstrate that the tribo-pairs of $\mathrm{NbN}$ and $\mathrm{Al}_{2} \mathrm{O}_{3}$ can also achieve ultra-low friction in a three-phase contact environment. Moreover, the friction coefficient is generally lower, between approximately 0.031 and 0.075 . According to the feasible friction mechanism proposed above, it can be assumed that a stable ultra-low friction phenomenon can be achieved while the "colloidal solution" - with a sufficient concentration of transition metal oxide colloidal particles - exists between the friction interfaces. Here, the other two common VB TMNs obtained under the same preparation conditions, namely TaN and VN with a standard cubic NaClstructure (Fig. S3 in the ESM) were used to perform friction tests under three different environments. After repeated trials, the results are shown in Fig. 6. The friction phenomena of the two VB TMNs are approximately the same as that of $\mathrm{NbN}$. In the three-
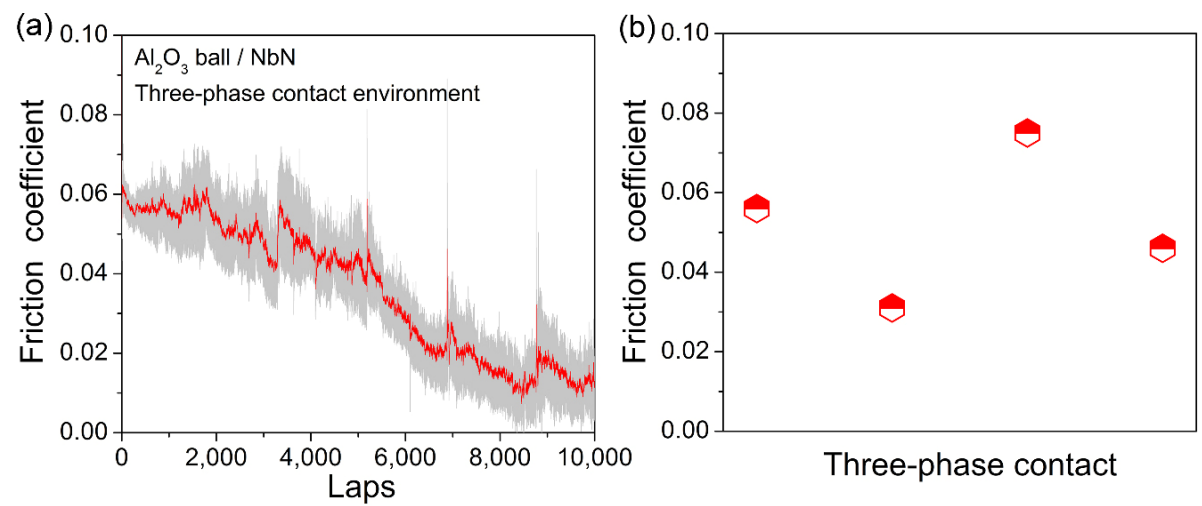

Fig. 5 (a) Measured friction coefficient vs. the number of cycles during the sliding of an $\mathrm{Al}_{2} \mathrm{O}_{3}$ ball on NbN in a three-phase contact environment and (b) friction coefficient distribution after multiple repeated tests.
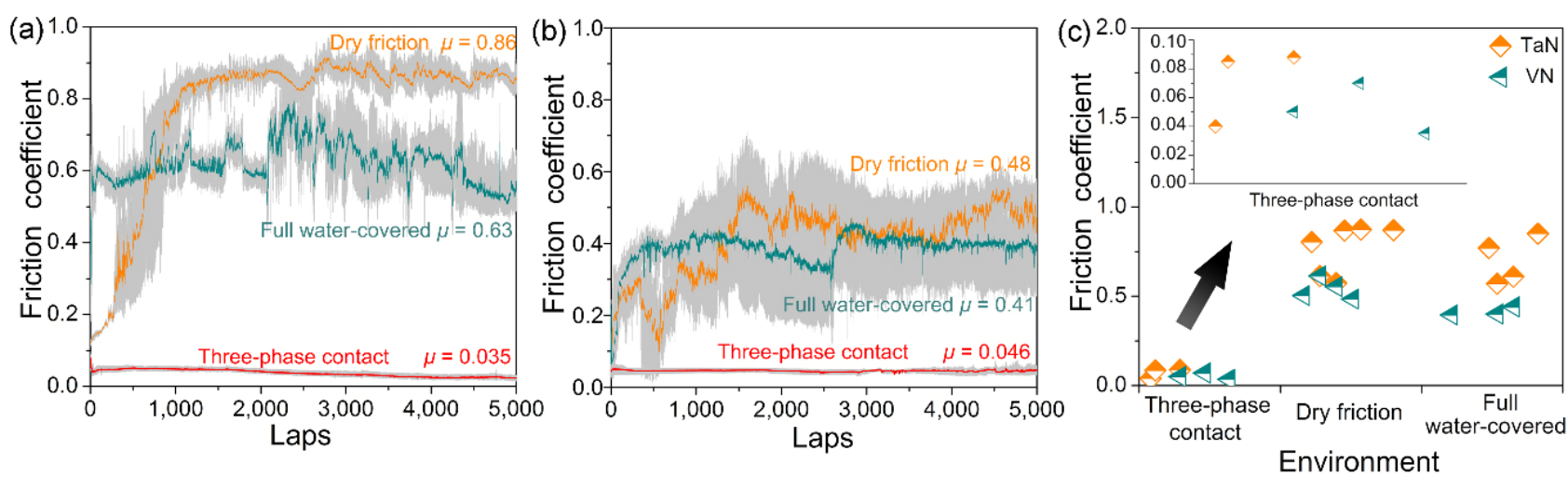

Fig. 6 (a) Measured friction coefficient $\mu$ vs. the number of cycles while sliding a stainless steel ball on TaN; (b) measured friction coefficient $\mu$ vs. the number of cycles during the sliding of a stainless steel ball on VN; and (c) friction coefficient distributions of TaN and $\mathrm{VN}$ after multiple repeated tests. 
phase contact environment, the friction coefficients are controlled to be very low, fluctuating in the range of $0.035-0.088$, while the friction coefficients are generally high in the other two environments. This further confirms our hypothesis and demonstrates that the VB TMNs system has the excellent properties of ultra-low friction and ultra-low wear in a threephase contact environment.

\section{Conclusions}

$\mathrm{NbN}$ with a typical cubic $\mathrm{NaCl}$-structure was prepared via magnetron sputtering, a three-phase $(\mathrm{NbN}$, water, and air) contact, atmosphere with $32 \%$ humidity, and fully water-covered environments were constructed to study the effect of water on the tribological behavior of $\mathrm{NbN}$. The three-phase contact environment makes the $\mathrm{NbN}$, air, and water contact each other during friction, contributing to the formation of a "colloidal solution" containing $\mathrm{Nb}_{2} \mathrm{O}_{5}$ colloidal particles between the friction interfaces. The formation of the double electric layer repulsion between the friction interfaces, together with the natural water-based weak shear capacity of the "colloidal solution", helps $\mathrm{NbN}$ to obtain a stable ultra-low friction phenomenon and the friction coefficient fluctuates between 0.04 and 0.09 . Simultaneously, the anti-wear capability is also demonstrated, which reaches an ultra-low wear rate of $\sim 10^{-10} \mathrm{~mm}^{3} \cdot \mathrm{N}^{-1} \cdot \mathrm{m}^{-1}$. However, too much or too little water between the friction interfaces is not conducive to the formation of three-phase contact, which greatly reduces the probability of ultra-low friction and wear. Tribo-tests of the other two VB TMNs further confirm the above views. These findings indicate that the VB TMNs are non-additive water-based lubricants with high mechanical strength; the discovery of this new water-solid composite lubrication system provides new ideas for designing distinct advanced lubrication and protection schemes.

\section{Acknowledgements}

This work was supported by the National Natural Science Foundation of China (Grant Nos. 51905206, 51972139, and 51602122), National Key R\&D Program of China (Grant No. 2016YFA0200400), the
China postdoctoral Science Foundation (Grant No. 2017T100207), the Program for JLU Science and Technology Innovative Research Team (2017TD-09), and the Fundamental Research Funds for the Central Universities.

Electronic Supplementary Material Supplementary material is available in the online version of this article at https://doi.org/10.1007/s40544-021-0492-2.

Open Access This article is licensed under a Creative Commons Attribution 4.0 International License, which permits use, sharing, adaptation, distribution and reproduction in any medium or format, as long as you give appropriate credit to the original author(s) and the source, provide a link to the Creative Commons licence, and indicate if changes were made.

The images or other third party material in this article are included in the article's Creative Commons licence, unless indicated otherwise in a credit line to the material. If material is not included in the article's Creative Commons licence and your intended use is not permitted by statutory regulation or exceeds the permitted use, you will need to obtain permission directly from the copyright holder.

To view a copy of this licence, visit http://creativecommons.org/licenses/by/4.0/.

\section{References}

[1] Brown S F. Base oil groups: manufacture, properties and performance. Tribol Lubr Technol 71(4): 32-35 (2015)

[2] Qu J, Luo H M, Chi M F, Ma C, Blau P J, Dai S, Viola M B. Comparison of an oil-miscible ionic liquid and ZDDP as a lubricant anti-wear additive. Tribol Int 71: 88-97 (2014)

[3] Biresaw G, Bantchev G B, Murray R E. Inv estigation of biobased and petroleum base oils in the entire spectrum of lubrication regimes. J Am Oil Chem Soc 94(9): 1197-1208 (2017)

[4] Dong R, Yu Q L, Bai Y Y, Wu Y, Ma Z F, Zhang J Y, Zhang C Y, Yu B, Zhou F, Liu W M, et al. Towards superior lubricity and anticorrosion performances of proton-type ionic liquids additives for water-based lubricating fluids. Chem Eng J 383: 123201 (2020)

[5] Tomala A, Karpinska A, Werner W S M, Olver A, Störi H. Tribological properties of additives for water-based lubricants. Wear 269(11-12): 804-810 (2010) 
[6] Guo P F, Qi S S, Chen L, Guo C X, Lin B, Lu Z B, Wu Z G, Zhang G A. Black phosphorus-graphene oxide hybrid nanomaterials toward advanced lubricating properties under water. Adv Mater Interfaces 6(23): 1901174 (2019)

[7] Ge X Y, Li J J, Luo R, Zhang C H, Luo J B. Macroscale superlubricity enabled by the synergy effect of grapheneoxide nanoflakes and ethanediol. ACS Appl Mater Interfaces 10(47): 40863-40870 (2018)

[8] Li J J, Zhang C H, Sun L, Lu X C, Luo J B. Tribochemistry and superlubricity induced by hydrogen ions. Langmuir 28(45): 15816-15823 (2012)

[9] Yue D C, Ma T B, Hu Y Z, Yeon J, Duin A V, Wang H, Luo J B. Tribochemistry of phosphoric acid sheared between quartz surfaces: A reactive molecular dynamics study. J Phys Chem C 117(48): 25604-25614 (2013)

[10] Li H, Wood RJ, Rutland MW, Atkin R. An ionic liquid lubricant enables superlubricity to be "switched on" in situ using an electrical potential. Chem Commun (Camb) 50(33): 4368-4370 (2014)

[11] Jiang C, Li W M, Nian J Y, Lou W J, Wang X B. Tribological evaluation of environmentally friendly ionic liquids derived from renewable biomaterials. Friction 6(2): 208-218 (2018)

[12] Ge X Y, Li J J, Zhang C H, Luo J B. Liquid superlubricity of polyethylene glycol aqueous solution achieved with boric acid additive. Langmuir 34(12): 3578-3587 (2018)

[13] An L L, Yu Y L, Bai C N, Bai Y Q, Zhang B, Gao K X, Wang X B, Lai Z P, Zhang J Y. Simultaneous production and functionalization of hexagonal boron nitride nanosheets by solvent-free mechanical exfoliation for superlubricant water-based lubricant additives. npj 2D Mater Appl 3(1): 28 (2019)

[14] Kumari S, Sharma O P, Gusain R, Mungse H P, Kukrety A, Kumar N, Sugimura H, Khatri O P. Alkyl-chain-grafted hexagonal boron nitride nanoplatelets as oil-dispersible additives for friction and wear reduction. ACS Appl Mater Interfaces 7(6): 3708-3716 (2015)

[15] Zhou F, Chen K M, Wang M L, Xu X J, Meng H, Yu M, Dai $\mathrm{Z}$ D. Friction and wear properties of $\mathrm{CrN}$ coatings sliding against $\mathrm{Si}_{3} \mathrm{~N}_{4}$ balls in water and air. Wear 265(7-8): 1029-1037 (2008)

[16] Long C G, Wang X Y. Wear and mechanical properties of Ekonol/G/MoS $2 /$ PEEK composites. J Mater Sci 39(4): 1499-1501 (2004)

[17] Zhang K, Liu C, Wen M, Chen Y N, Song J L, Yang L N, Cao J S, Yu S S. Doping $\mathrm{Cu}$ atoms excel as the functional material to tune the wettability for TMeNs hard coating. Adv Mater Interfaces 5(18): 1800391 (2018)

[18] Liu C, Gu X L, Yang L N, Song X Q, Wen M, Wang J, Li Q, Zhang K, Zheng W T, Chen C F. Ultralow-friction and ultralow-wear TiN-Ag solid solution coating in base oil. J Phys Chem Lett 11(5): 1614-1621 (2020)

[19] Zhang K, Balasubramanian K, Ozsdolay B D, Mulligan C P, Khare S V, Zheng W T, Gall D. Growth and mechanical properties of epitaxial $\mathrm{NbN}(001)$ films on $\mathrm{MgO}(001)$. Surf Coat Tech 288: 105-114 (2016)

[20] Gassner G, Mayrhofer P H, Kutschej K, Mitterer C, Kathrein M. A new low friction concept for high temperatures: Lubricious oxide formation on sputtered VN coatings. Tribol Lett 17(4): 751-756 (2004)

[21] Molarius J M, Korhonen A S, Harju E, Lapplainen R. Comparison of cutting performance of ion-plated $\mathrm{NbN}, \mathrm{ZrN}$, TiN and (Ti, Al)N coatings. Surf Coat Tech 33: 117-132 (1987)

[22] Luo Q. Temperature dependent friction and wear of magnetron sputtered coating TiAlN/VN. Wear 271(9-10): 2058-2066 (2011)

[23] Singh K, Krishnamurthy N, Suri A K. Adhesion and wear studies of magnetron sputtered $\mathrm{NbN}$ films. Tribol Int 50: 16-25 (2012)

[24] Mamun M A, Farha A H, Er A O, Ufuktepe Y, Gu D, Elsayed-Alib H E, Elmustafa A A. Nanomechanical properties of $\mathrm{NbN}$ films prepared by pulsed laser deposition using nanoindendation. Appl Surf Sci 258(10): 4308-4313 (2012)

[25] Erdemir A, Ramirez G, Eryilmaz O L, Narayanan B, Liao Y, Kamath G, Sankaranarayanan S K. Carbon-based tribofilms from lubricating oils. Nature 536(7614): 67-71 (2016)

[26] Qi Z B, Wu Z T, Zhang D F, Zuo J, Wang Z C. Microstructure, mechanical properties and oxidation behaviors of magnetron sputtered $\mathrm{NbN}_{x}$ coatings. J Alloys Compd 675: 22-30 (2016)

[27] Jouve G, Séverac C, Cantacuzène S. XPS study of NbN and (NbTi)N superconducting coatings. Thin Solid Films 287: 146-153 (1996)

[28] Alfonso J E, Buitrago J, Torres J, Marco J F, Santos B. Influence of fabrication parameters on crystallization, microstructure, and surface composition of $\mathrm{NbN}$ thin films deposited by rf magnetron sputtering. J Mater Sci 45(20): 5528-5533 (2010)

[29] Darlinski A, Halbritter J. Angle-resolved XPS studies of oxides at $\mathrm{NbN}, \mathrm{NbC}$, and $\mathrm{Nb}$ surfaces. Surf Interface Anal 10: 223-237 (1987)

[30] Alfonso J E, Buitrago J, Torres J, Marco J F, Santos B. Influence of fabrication parameters on crystallization, microstructure, and surface composition of $\mathrm{NbN}$ thin films deposited by rf magnetron sputtering. J Mater Sci 45(20): 5528-5533 (2010)

[31] Stone D S, Migas J, Martini A, Smith T, Muratore C, Voevodin A A, Aouadi S M. Adaptive NbN/Ag coatings for high temperature tribological applications. Surf Coat Technol 206(19-20): 4316-4321 (2012)

[32] Rusty M P, Alexis T B. Raman studies of the structure of $\mathrm{Nb}_{2} \mathrm{O}_{5} / \mathrm{TiO}_{2}$. J Phys Chem 97: 12178-12185 (1993) 
[33] Dai X, Wen M, Wang J, Cui X R Wang X, Zhang K. The tribological performance at elevated temperatures of MoNbN-Ag coatings. Appl Surf Sci 509: 145372 (2020)

[34] Jehng J M, Wachs I E. Structural chemistry and Raman spectra of niobium oxides. Chem Mater 3(1): 100-107 (1991)

[35] Graciani J, Fernández Sanz J, Márquez A M. A density functional study of initial steps in the oxidation of early transition metal nitrides, $\mathrm{MN}(\mathrm{M}=\mathrm{Sc}, \mathrm{Ti}$, and $\mathrm{V}) . J$ Phys Chem C 113(3): 930-938 (2009)

[36] Glaser A, Surnev S, Netzer F P, Fateh N, Fontalvo G A, Mitterer C. Oxidation of vanadium nitride and titanium nitride coatings. Surf Sci 601(4): 1153-1159 (2007)

[37] Li D, Muller M B, Gilje S, Kaner R B, Wallace G G. Processable aqueous dispersions of graphene nanosheets. Nat Nanotechnol 3(2): 101-105 (2008)

[38] Zhang S W, Zhang C H, Hu Y Z, Ma L R. Numerical simulation of mixed lubrication considering surface forces. Tribol Int 140: 105878 (2019)

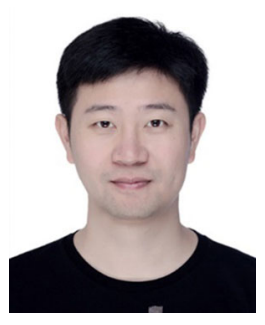

Kan ZHANG. He received his B.S. and Ph.D. degrees from Jilin University in 2007 and 2014, respectively. He is now working as the "Tang Aoqing" professor in the Department of Materials Science and State Key Laboratory of Superhard

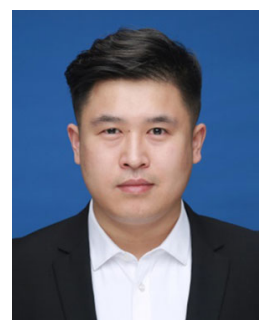

Jia WANG. He received his Ph.D. degree from Lanzhou Institute of Chemical Physics, Chinese Academy Science, China, in 2016. After that, he spent two years at the Key Laboratory of Automobile Materials,

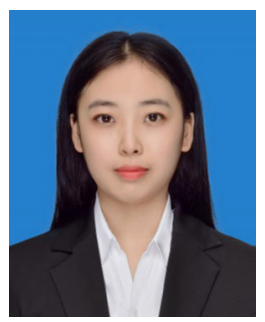

Kaifei MIAO. She received her B.S. degree in engineering from Wei Fang University, China, in 2018. In the same year, she began to study
[39] Klein J. Hydration lubrication. Friction 1(1): 1-23 (2013)

[40] Hamrock B J, Dowson D. Isothermal elastohydrodynamic lubrication of point contacts: Part III-Fully flooded results. J Lubr Technol 99(2): 264-276 (1977)

[41] Wang H D, Liu Y H, Li J J, Luo J B. Investigation of superlubricity achieved by polyalkylene glycol aqueous solutions. Adv Mater Interfaces 3(19): 1600531 (2016)

[42] Dai X, Wen M, Huang K K, Wang X, Yang L N, Wang J, Zhang K. Toward low friction in water for $\mathrm{Mo}_{2} \mathrm{~N} / \mathrm{Ag}$ coatings by tailoring the wettability. Appl Surf Sci 447: 886-893 (2018)

[43] Zuo Q Y, Lai T M, Huang P. The effect of the electric double layer on very thin thermal elastohydrodynamic lubricating film. Tribol Lett 45(3): 455-463 (2012)

[44] Raviv U, Klein J. Fluidity of bound hydration layers. Science 297(5586): 1540-1543 (2002)

[45] Raviv U, Perkin S, Laurat P, Klein J. Fluidity of water confined down to subnanometer films. Langmuir 20(13): 5322-5332 (2004)

Materials, Jilin University. His research focuses on the superhard/hard thin films. In this area, he has published 67 peer-reviewed papers indexed by SCI, and has authorized 14 invention patents. He won the Jilin Province Outstanding Youth Science Fund (2017) and IFAM Outstanding Young Scientist Award (2020).

MOE, Jilin University, China, for postdoctoral research. He is currently a lecturer at Jilin Jianzhu University, China. His research interests cover lubricating oil/grease, carbon-based coating materials, transition metal nitride coatings, and the related tribological properties.

for her M.S. degree in engineering at Jilin University. Her current research is the tribological behaviors and frictional mechanisms of transition metal nitrides (borides). 